\title{
OPEN
}

\section{6 \\ The Future Panel on Public Health Genomics - Lessons Learned and Future Perspectives}

\author{
André Krom, Mara Almeida, Leo Hennen, Edgaras \\ Leichteris, Arnold Sauter and Dirk Stemerding
}

\begin{abstract}
Krom et al. give an in-depth account of a methodological experiment carried out in the PACITA project, namely the application in a cross-European context of the Future Panel method. Focusing on the complex issue of genomics and its potential use in public health care, parliamentarians from different countries were gathered to learn about and debate this far-reaching field of research in order to create a foundation for proactive policy formulation. The authors analyse and evaluate the project setup and argue that while further development and institutional is necessary to make similar future projects reach their full potential, the project nevertheless exemplifies the practicability and value of applying previously nationally contained TA methods in a cross-European setting.
\end{abstract}

Klüver, Lars, Rasmus Øjvind Nielsen, and Marie Louise Jørgensen, eds. Policy-Oriented Technology Assessment Across Europe: Expanding Capacities. Basingstoke: Palgrave Macmillan, 2016. DOI: 10.1057/9781137561725.0016. 
Technology constantly pushes the bounds of what medical care can achieve and at what cost. Although medical care is a highly expert-driven field, parliamentarians and government decision makers nevertheless become involved in shaping medical innovation through funding decisions and framework regulations. If such interventions are to be both legitimate and effective, they must be made on the basis both of sound evidence and of open dialogue regarding possible pathways. Designing processes to ensure such quality in policy making is a key example of the role that technology assessment (TA) institutions can play as mediators between science and policy. To exemplify this role to European policy makers, PACITA carried out an experiment in cross-national policy dialogue on Public Health Genomics (PHG).

PHG is often understood as the responsible and effective translation of genome-based information and technologies (GBITs) into health-care practices. It is regarded as a central future perspective for the medical system. According to some experts, PHG will make health care truly personalized, predictive, preventive and participatory. However, there is still a high degree of scientific uncertainty about what PHG can actually deliver. There are also far-reaching ethical, legal and socioeconomic questions related to GBITs. Therefore, an in-depth societal and political debate on PHG is of fundamental importance for the future health-care system.

TA has already played an important role in the public and political discourse in many countries, by systematically collecting inter- and trans-disciplinary knowledge and by stimulating and organizing debate between different stakeholders. Given the rapid scientific progress and many challenges for policy making in the foreseeable future connected to PHG, an expert-based methodology - the Future Panel - was chosen. The central idea behind the Future Panel method is to connect the scientific and the political discourse in a new and constructive way. In general, the method is well suited to far-reaching topics that require central political initiatives and action and where there is a desire to act proactively. The method had originally been developed and applied in a national context. In this project, the Future Panel (FP) was formed by parliamentarians from different European member states and the European Parliament with a specific responsibility for health policy. This was a methodological experiment because the FP method had to be adapted to a cross-national context.

As an example project, the FP on PHG succeeded in contributing to the central aim of PACITA - to induce mutual learning on setting 
up support platforms for knowledge-based decision making among the European countries involved. The project also managed to provide relevant input for policies on Public Health Genomics in terms of an overview of state of affairs and policy options. Developments in PHG hold the promise to be beneficial for individuals and to promote public health. However, given a range of uncertainties and ambiguities related to GBITs, the responsible introduction of GBITs in health-care systems requires an incremental approach.

As a methodological experiment, the project did not meet all of its objectives, including the aim to connect the scientific and political discourse on Public Health Genomics in a new and constructive way. Due to the complexity of the topic and the specific restriction of time and resources, detailed discussions of options for policy intervention and regulation of existing practices and regulatory stipulations for different fields of application were not possible. Through its broad approach, however, the project and its documented outcomes are useful to raise sensitivities for problems to be expected and thus can serve as a starting point for a more detailed evaluation of single GBIT applications and health-care practices on the European level and the national level.

\section{Background}

The aims of the demonstration project were to provide a concrete and policy-relevant example on EU-level coordinated parliamentary TA by:

- giving input to policy making on policies on Public Health Genomics, in terms of an overview of state of affairs and policy options; ${ }^{1}$

- establishing a national/regional-level and EU-level experience with a coordinated expert-based TA method that involves parliamentarians;

- doing this in cooperation with decision makers on the national/ regional level and the EU-level, in order to create experience on, and thereby mobilization around, the use of such methods among the main users;

- doing this in cooperation with the scientific community on Public Health Genomics in order to create learning and mobilization on the potential of expert-based policy making facilitated by TA specialists; and 
- involving countries that have not established such institutions and methods directly in their work, in order to build capacity, create learning and mobilize the actors.

The idea of installing a panel of parliamentarians to discuss long-term political issues related to developments in science and technology was not new. An example of an earlier and comparable initiative is the Finish Committee for the Future. Based on parliamentary proposals going back to 1986, a Committee for the Future was appointed in 1993 on a temporary basis. In the year 2000 , the Committee received permanent status. ${ }^{2}$ Building on the Finish experience, the Danish Board of Technology developed the Future Panel method. This method involves a temporary panel, typically for a period of $1 \frac{1 / 2-2}{\text { years, the activities }}$ of which revolve around intensive collaboration between the Future Panel and invited experts from relevant practices related to the topic at hand.

Like the Danish Future Panel method, the PACITA Future Panel involved a temporary panel of parliamentarians and the collaboration of the Future Panel and invited experts. Important differences were that the project on Public Health Genomics involved a cross-national Future Panel, that the interaction between the Future Panel and the invited experts was less extensive and that there was no institutional link between the project and the respective parliaments of the FP members: they were invited as individual members of parliament. This meant that the method had to be adapted for use in a cross-national context. In a sense, then, the 'Future Panel on Public Health Genomics' was a methodological experiment.

\section{The Future Panel project: process, participants and outcomes}

The Future Panel project on Public Health Genomics consisted of three stages. In the first stage, the precise scope of the project was defined during a kick-off meeting that involved the Future Panel, which resulted in a list of policy issues that were identified as most relevant for further investigation. During the second and main stage of the project, which took a full year, policy issues and options for public health genomics were discussed and elaborated in different expert working groups (EWGs) and in a policy options workshop. The final stage was a Policy 
Hearing in which the Future Panel discussed the main outcomes of the project with invited experts.

The main target group of the project was the Future Panel, consisting of parliamentarians with a specific responsibility for health policy. The panel had four members, who represented different parties in the political spectrum, including one member of the European Parliament and three members of national parliaments (Denmark, Portugal and Switzerland). The main role of the FP was to co-define a research and policy agenda at the start of the project and to discuss, during the final Policy Hearing, the issues and options articulated by a range of experts on different aspects of PHG who were involved in the course of the project.

The project was carried out by a task team of TA practitioners from the four countries involved in the PACITA consortium. ${ }^{3}$ As in all subprojects of PACITA, partners were from both countries with and countries without established institutes for (parliamentary) technology assessment (see Table 6.1). A group of five external experts on different aspects of public health genomics was involved as a steering group to assure the high quality of all project activities. Four international expert working groups were responsible for the investigation and articulation of policy issues and options for public health genomics in a year-long process of collaboration with the task team and the expert steering group.

\section{Stage 1: defining an evidence-based policy agenda}

As an expert-based methodology, the Future Panel on Public Health Genomics was based on the assumption that policies relating to future developments in this field should be evidence based. 'Evidence' should be taken in a broad sense here: the issues raised by the introduction of genome-based information and technologies in future health care involve not only complex scientific questions but also a history of controversial ethical, social and legal debate concerning highly sensitive areas of medical care, such as prenatal diagnosis and genetic screening. Four international EWGs were composed of experts on precisely these issues. The Future Panel had a pivotal role at the start of the project in identifying the issues that would require further research, deliberation and political action: to ensure the political relevance of the expert-based analysis and policy options to be deliberated in the final policy hearing. During the kick-off meeting of the project, these issues were defined in a discussion with the steering group and task team, resulting in a research 
and policy agenda that raised questions that could serve as input for the ensuing investigations in the four expert working groups.

\section{Stage 2: Exploring the field}

With this research and policy agenda as a starting point, the evidence produced by the expert working groups during the second stage of the project covered not only technical state-of-the-art scientific knowledge but also a broad range of other relevant issues raised by developments in the field of public health genomics. The task of the working groups was to produce twenty-page reviews of: (1) the state of human genome research and its prospects for future medical applications in public health genomics; (2) issues of quality assessment relating to the clinical validity and utility of genome-based medical applications and practical experience in public health genomics; (3) the possible economic and structural effects of public health genomics on the public health system; and (4) the ethical, social and legal aspects of public health genomics. In reviewing these different topics, the expert working groups not only engaged themselves with the Future Panel policy agenda in more or less direct ways but also reframed this agenda by putting the issues in a broader context of current and potential future developments and challenges in the field of public health genomics. Based on this review, the role of the EWGs further included the articulation of policy options suggesting different ways in which policy makers might deal with the issues raised by future prospects in public health genomics. ${ }^{4}$

The efforts of the expert working groups were coordinated by the task team members, who also had the responsibility to summarize the four working group reports in an expert paper that described in a concise and accessible way the challenges and policy issues that were identified by the experts as most salient and urgent. ${ }^{5}$ The expert paper was the central input for the policy options workshop.

The policy options workshop brought together experts from the four working groups and members of the expert steering group and task team, allowing the project participants to further increase the focus of their main findings and to 'translate' into policy options the rather divergent perspectives on public health genomics represented in the project. The results were integrated in a policy brief that served as the main input for the concluding policy hearing. ${ }^{6}$ 
TABLE 6.1 Items highlighted in Policy Brief on Public Health Genomics

\author{
Issues related to medical genomics research \\ Data sharing and intellectual property \\ 'Big data' security and privacy \\ Quality assessment \\ From research to clinical practice \\ What to screen for and when \\ Patients' rights and professional responsibilities \\ Informed consent and service provision \\ Governance in public health genomics \\ Need for an incremental and programmatic approach
}

\title{
Stage 3: a new policy agenda?
}

During the final policy hearing, the Future Panel again played a pivotal role. The hearing was organized as a public meeting in which the Future Panel had the opportunity to discuss with three panels of experts the main items highlighted in the policy brief (see Table 6.1). The aim of the policy hearing was to provide more fine-grained clarifications and suggestions related to the policy questions and issues that were formulated by the FP members at the start of the project. In this way, the FP members would gain a better understanding of the issues involved. Providing information that takes into account the different views on public health genomics would support the FP members in their work in parliament.

\section{The Future Panel as a TA demonstration project - main achievements and implications}

As a TA demonstration project, the Future Panel on Public Health Genomics did quite well. To start with, it successfully contributed to the central aim of PACITA, which is to induce mutual learning in support of the establishment of platforms for knowledge-based decision making among the involved European countries (in this case Germany, Lithuania, Portugal and the Netherlands). One example of this has already been mentioned, namely the fact that at the start of the project none of the task team partners had prior experience with the Future Panel method. Over the course of the project, all partners gained experience not only in 
actually applying the method but also in adapting the method and applying it in an entirely new context: a clear example of mutual learning. Another example is the fact that the Portuguese partner Instituto de Technologia Quimica e Biologica (ITQB), who got involved in PACITA as a so-called non-PTA country, is now a participant in another TA project that relate to public health genomics, focusing on the 'genetics clinic of the future'.

The project also provided relevant input for policies on public health genomics in terms of an overview of the state of affairs and policy options. It succeeded in involving a broad range of European genomics experts as members of the Working Groups. For instance, interim results of the project have been presented during a satellite meeting of the 2013 conference of the European Society for Human Genetics. Policy makers and practitioners from the countries that were involved were provided with the best available expert knowledge on GBITs and could gain practical experience with TA as a practice of democratic and transparent knowledge-based policy consulting. The complete interactive exercise of Expert Working Groups, Policy Options Workshop and stakeholder consultation support the notion that developments in public health genomics hold the promise to be beneficial for individuals and to promote public health. However, a crucial insight from this process is also that, given a range of uncertainties and ambiguities, the responsible introduction of GBITs in health-care systems requires a careful step-bystep approach that involves a broad societal and political debate about the direction in which health-care systems should develop.

The Future Panel process highlighted two major shifts connected to developments in public health genomics that challenge traditional boundaries in health care. First, the introduction of GBIT in health-care systems challenges the boundary between research and clinical care. It entails complex data flows that raise a number of issues relating to infrastructure demands, intellectual property, data security, tensions between the needs of research and the needs of the individual, patient rights and professional responsibilities, and the potential feedback of (re) analysed data. Second, the introduction of GBIT in health-care systems challenges the boundary between clinical care (particularly diagnostics) and screening. Both diagnostics and screening generate potentially large amounts of information about an individual's genome and raise new and challenging issues concerning quality assessment and how to deal with unsolicited information that might result from these tests. These issues could arise in a variety of health-care settings as whole genome 
sequencing tests find further application in established and new practices of screening. Consequently, the responsible introduction of GBITs in the health-care system requires an early dialogue in which these stakeholders are actively involved.

The ambition of the project was to deal with the full scope of possible future applications of GBITs, such as pre-implantation and prenatal genetic diagnostics, new-born and adult screening programmes, and whole genome sequencing for general medical services. This broad scope was indispensable for an evidence-based evaluation of the pros and cons. The timespan of the project, however, did not allow for detailed discussions of options for policy intervention and regulation or of existing practices and regulatory stipulations for each of the fields of application. Also, a more in-depth analysis of the state of practice in the different countries involved was not possible. Through its broad approach, however, the project has helped to increase stakeholders' sensitivity to foreseeable problems and thus can serve as a starting point for more detailed evaluations of single applications of GBITs and healthcare practices on the European level as well as on the national level.

\section{The Future Panel on PHG as a methodological experiment}

Up until the PACITA project, the Future Panel method had been used twice by the Danish Board of Technology (DBT). ${ }^{8}$ Methodologically, there were clear similarities between the design of the 'original' Future Panel (OFP) as developed by the DBT and the PACITA Future Panel (PFP). Both the OFP and the PFP lasted approximately $1 \frac{1}{2}$ to 2 years and started with an introductory seminar in which the Steering Group and Future Panel met for the first time to jointly determine the focus of the project. Like the OFP, the PFP aimed to gather existing knowledge on the central theme in connection with debate and assessment, to create an overview and elucidate the political tasks connected to the theme. Again, like the OFP, the PFP relied heavily on the input of experts to feed into the policy-making process.

However, there were also important differences between the original Future Panel and the PACITA variant. For the purposes of this chapter, we will mention five of them that contributed to the project being a methodological experiment. ${ }^{9}$ 
- First, while the OFP was developed for and applied in a national context, the PFP involved adjusting this method to and applying it in a cross-national context. It was in this cross-national context that the TA demonstration had to contribute to the broader aims of PACITA: by establishing a national/regional-level and EU-level experience with a coordinated expert-based TA method that involved parliamentarians; by doing this in cooperation with decision makers on the national/regional level and the EU-level, in order to create experience on, and mobilization around, the use of such methods among the main users; by doing this in cooperation with the scientific community on public health genomics in order to create learning and mobilization on the potential of expert-based policy making facilitated by TA specialists; and by involving countries that have not established such institutions and methods directly in their work, in order to build capacity, create learning and mobilize the actors.

- A second important difference between the OFP and PFP was that in the OFP panel members were appointed by parliament, thereby forging a strong institutional link between parliament and the project. In the PFP, on the other hand, individual members of parliament were invited by the PACITA consortium. In other words, in the OFP, there was no institutional link between the respective parliaments of the Future Panel members and the project.

- As a result, and this is the third important difference, the work done by the PFP worked at a greater distance from actual political committee work compared to the OFP. Typically, work done by the OFP can be regarded as provisional political committee work.

- Fourth, the OFP and the PFP differed with regard to the political representation in the Future Panel, both with regard to the political spectrum and the parliamentary committees involved. In the OFP, all political parties were represented, as well as a wide range of political committees. This was not the case in the PFP. There was some political diversity, but not all political parties (from all participating countries) were involved. In addition, members of the PFP were all connected to a parliamentary committee with a special responsibility for health-care policy. ${ }^{10}$

- Finally, there was an important difference between the OFP and the PFP concerning the number of public hearings that were 
organized as part of the project. Whereas the OFP typically involved four public hearings, the PFP involved one public hearing, complemented by the possibility of consulting the FP members on an ad hoc basis.

\section{Lessons learned and future perspectives}

Based on our experiences with the project, we will now present a number of lessons learned about the Future Panel method as a model for evidence-based and anticipatory TA in a broad international context. With these lessons, we would like to address first of all policy makers and civil servants wanting to support cross-European TA.

\section{Lesson 1: Establish a connection with parliaments and/or ministries, in addition to their respective individual members}

Contrary to the standard model, Future Panel members in the project on public health genomics were not appointed by parliament(s) but invited by the PACITA consortium. More specifically, the members were (primarily) invited as individual members of parliament based on their particular individual expertise. In addition, the experimental character of the project entailed that the project activities were not directly tied to an explicit mission by a policy-making body. This meant that the work of the Future Panel and the expert working groups started at a greater distance from parliament compared to the standard model. One of the positive outcomes of doing cross-European TA is to provide an opportunity to debate specific issues which are not on the front line of national political discourses but which are in need of urgent consideration and reflection in a European context. As noted, the members of the Future Panel indicated that a possible action following the final policy hearing would be to present the issues discussed in their respective parliaments. Thus, the function of establishing more direct links to national parliaments would be to attain a more clear 'mandate' to offer policy options not to individual members of different parliaments only, but to their respective parliaments as well.

Parliaments may have less policy-making power in some countries than they do in other countries. Moreover, experience with evidencebased policy making may be concentrated not in parliament, but in the government or the ministries. If the aim of a project is to promote and 
to mobilize experience with evidence-based policy making on a certain topic, then at least with regard to these countries, we would recommend not to focus exclusively on parliamentarians but to invite policy makers from the government and/or ministries as well.

\section{Lesson 2: Establishing a solid evidence base for policy making requires an iterative process that involves direct contact between all actors directly involved in the project}

By organizing multiple public hearings, the standard model automatically allows for an iterative process that involves direct communication between the Future Panel and the experts, and between the Future Panel and the steering group. At the start of the PACITA Future Panel, it was indicated that the panel could be consulted during the process on an ad hoc basis. Such consultation was done once, allowing the steering group and the expert working groups to receive feedback on the draft reports of EWGs 1 and 2. However, organizing the contact in this ad hoc way meant that this round of consultation was positioned as something extra, not as an integral part of the process. Moreover, apart from the concluding policy hearing, communication between the FP and the experts in the PACITA project was always mediated by members of the task team. As a result, the project allowed for relatively few opportunities to check whether there was an adequate match between the policy issues and questions raised by the Future Panel, on the one hand, and the findings from the expert working groups, the expert paper and the policy brief, on the other.

Explicitly building an iterative process into the project design would also increase the possibilities to map and to manage mutual expectations. For instance, feedback from the Future Panel after the policy hearing made clear that some members would have expected more practical answers to the questions and issues that the panel formulated at the start of the project. On the other hand, evaluation of the expert working groups showed that not having a clear mandate to offer policy-making solutions raised questions pertaining to the role of the EWG's and may have affected the motivation of individual EWG members to articulate and reflect on particular policy options.

We highly recommend, therefore, to include in the project design of the Future Panel method, an iterative process that involves direct contact between all involved in the project: (1) between the Future Panel and the experts involved; (2) between the Future Panel and the steering 
group; (3) between the members of the Future Panel; and (4) between the experts from the different expert working groups. Especially in the context of cross-European TA, this will require considerably more time and a larger budget than was available for the PACITA demonstration project.

\section{Lesson 3: Different experience of EU countries with evidence-based policy making are a challenge.}

An important aspect of the project 'Future Panel on Public Health Genomics' was cooperation between PTA and non-PTA countries. One respect in which these countries may differ is in terms of the extent to which they have experience with evidence-based policy making. In Lithuania, for example, which is one of the non-PTA partners, links between policy making, on the one hand, and the scientific community or society, on the other hand, are weak. This presents a challenge in general but particularly with respect to long-term policy making on relatively advanced technologies, such as GBITs in health care. Part of that challenge is that some of the non-PTA countries struggle with a lack of basic research and clinical capacities at medical facilities. There may be a clear need in this respect for mutual learning on evidence-based policy making. But it also presents quite a challenge for attaining a clear focus of the policy debate when a participating country is struggling to cover basic needs that need to be met in the short term while the TA debate is focused on long-term visionary goals that involve high-tech such as GBITs. One of the main challenges is the capacity to translate the outcomes of cross-European TA at the national level, taking into account the differences in health-care systems in Europe, technological developments, and financial investments being made into research.

One way of meeting that challenge would be to discuss the potential introduction of GBITs in the context of the sustainability of a diversity of health-care systems in different countries. In other words, for a more relevant and significant impact, cross-European TA should have a clear aim of having a European, national and local integration of results. In the case of the Future Panel on Public Health Genomics, it would thus have been important for small studies to be produced, where the main conclusions of the activity would be analysed considering different national contexts. This would allow the possibility of integrating global and local perspectives, highlighting the main issues of concern, including issues of consensus as well as issues of dissidence. However, this was 
not defined as part of the activity, and therefore, there was no time and budget allocated to it.

\section{Lesson 4: Concerning the role of TA experts, maintain a constructive balance between the role as secretariat and the capacity needed to function as TA specialists}

One of the aims of the project was to create learning and mobilization on the potential of expert-based policy making facilitated by TA specialists. In this context, cross-European TA provides unique opportunities to support the development of a collaborative framework between countries with a long experience in doing TA and countries currently initiating TA activities. In practice, however, and mainly due to time and budget constraints, the TA experts involved in the PACITA Future Panel project had to function predominantly as the secretariat of the project. This left insufficient time to properly exchange experiences and expertise between the PTA and non-PTA partners when bringing together the rich and diverse results from the expert working groups in a systematic, constructive and policy-relevant way. One of the ways in which this could be countered would be to more directly involve experienced TA experts from PTA countries in the EWG activities that were led by the non-PTA countries. The fourth lesson learned from the Future Panel on Public Health Genomics, then, is that concerning the role of TA experts, a constructive balance must be maintained between the role as secretariat and the capacity needed to properly function as TA specialists. This lesson also underlines the crucial importance of TA capacity building in non-PTA countries.

\section{Notes}

1 These were the aims of the project as specified beforehand (the 'theory'). At several points, there were (small) differences between theory and practice. See A. Krom and D. Stemerding (2014).

2 See http://web.eduskunta.fi/Resource.phx/parliament/committees/future. htx?lng=en.

3 Not long after the start of the project work package (WP), leader IST (Institute Society and Technology) from Belgium was discontinued. The Rathenau Instituut, not previously involved in this WP, took over the role of WP leader.

4 See Expert Working Groups on Public Health Genomics (2013). 
5 See D. Stemerding and A. Krom (eds) (2013).

6 See D. Stemerding and A. Krom (2014).

7 'Why should policy-makers care about public health genomics? Towards a policy agenda' (Paris, 9 June), https://www.eshg.org/satmeetings2013.o.html.

8 In the year 200o, the method was used in a project on the ageing population and in 2005 in a project on Denmark's future energy system. See e.g. Hennen et al. (2004).

9 For a more elaborate comparison, see A. Krom and D. Stemerding (2014).

10 Early on in the project the relative low number of Future Panel members was identified as a potential risk to the project. Subsequently, extensive attempts were made to further expand the panel.

(c) Except where otherwise noted, this work is licensed under a
Creative Commons Attribution 4.0 Unported License. To view a copy of this license, visit https://creativecommons.org/version4 